\title{
Droplet behaviors of a spray impinging on an oil film by planar laser induced fluorescence

\author{
Lei Feng ${ }^{1}$, Zhenyang Ming ${ }^{1}$, Haifeng Liu*1, Yanqing Cui ${ }^{1}$, Mingsheng Wen ${ }^{1}$, Mingfa Yao ${ }^{1}$ \\ ${ }^{1}$ State Key Laboratory of Engines, Tianjin University, China
}

\begin{abstract}
Microscopic characteristics of a spray impinging on an oil film have a great influence on the atomization and pollutant emissions. Therefore, the droplet behaviors from the impinging spray and oil film are significantly important to evaluate the spray/film process and need to be deeply understood. In this study, under different viscosity and thickness of the oil film, the droplet behaviors from a spray after impinging on an oil film at different locations were analysed by planar laser induced fluorescence. Results showed that an obvious crown structure is generated after the spray impinged on the oil film in the selected conditions. With the rise of viscosity of the oil film, the crown size becomes larger and larger size droplets are generated. The droplet diameter with maximum frequency and the maximum droplet diameter both display an increase trend as the viscosity rises. However, the maximum droplet velocity declines. The crown structure gets smaller and fewer droplets with large size and low velocity are generated when the oil film thickness declines from 0.5 to $0.2 \mathrm{~mm}$. Besides, a decreasing total number of droplets and a higher probability of relatively smaller droplets are observed at smaller oil film thickness condition. On the contrary, the diameters with maximum frequency are comparable for two film thicknesses. The maximum droplet velocity enlarges as the oil film thickness decreases.
\end{abstract}

Keywords: Droplet behaviors; Oil film; Corona splash

\section{Introduction}

Spray/wall interaction is a frequent phenomenon appearing in internal combustion engines. Although researchers have studied for decades, the complex interactions between the incident spray and wall are still far from being fully understood. Recently, the development of compact high-speed engines has attracted the attention in the impingement of sprays on solid walls. In addition, many advanced clean combustion technologies have been realized adopting the strategy of early injection. However, due to the short distance between injection nozzle and combustion chamber wall surface, and the high injection pressure, the fuel spray may impinge on the wall surface, especially the cylinder liner with lubricating oil film, before it is fully vaporized. It is considered as a source of soot and unburned hydrocarbon emissions and more research on this is needed.

The impact of individual droplets has been extensively used to describe the behaviour of spray impact and to predict its outcome. Yarin and Weiss [1] studied the impact of drops impinging one by one on a solid surface with an ethanol film. The secondary-droplet size distributions and total volume of these droplets were measured, and the splashing threshold was found as a function of the impact parameters. Experimental results concerning crown formation during liquid drop impact on wetted surface have been reported by Rioboo et al. [2]. On the basis of experimental observations, crown-splash and deposition-crown limits were determined using a combination of Weber and Ohnesorge numbers versus dimensionless film thickness. Vander Wal et al. [3, 4] explored the effects of fluid films of variable depths on droplets impacting on them. The size distribution and number of the splash products were measured and varied substantially depending upon the presence and 
relative thickness of the surface film. However, there is a known fact that a spray does not behave exactly as a summation of individual droplets. Yu, Liang, Zhang et al. [5-9] carried out some research with respect to the interaction between sprays and wetted walls. The impingement spray radius and height, wall film distribution, wall film area and average thickness were quantified. It was shown that spray impingement against a wall covered with a lubricant oil film tended to increase impingement spray radius while decreasing impingement spray height. With the increase of injection pressure and impingement angle, wall film area increased while average thickness decreased. The wall film area and average thickness both increased during the rise of impingement distance. Kambe et al. [10] studied sprays impinging on lubricating oil film and measured fuel film thickness and oil film thickness simultaneously. A large difference of deposition amount between the conditions of fuel spray impinges dry wall and lubricating oil film was observed. Due to the influence of lubricating oil film, deposition area and amount decreased compared with dry wall.

Although aforementioned researches have been fulfilled, the phenomena of sprays impinging on wetted walls still call for a detailed record of drop size, velocity and number flux near the impacted surface. The objective of this study is to measure the droplet behaviors from a spray impinging on an oil film in the near wall region. The droplets at different locations were analyzed by planar laser induced fluorescence (PLIF). The velocity of droplets was determined by using an open-source code, PIVlab, in MATLAB. The effects of viscosity and thickness of oil film on droplet behaviors were quantified.

\section{Experimental Apparatus and Methods}

The schematic diagram of experimental apparatus is shown in Figure 1. The experiments were carried out in a constant volume vessel at room temperatures and pressures. On the upper half of the vessel, each of the four sides was installed with a hollow window. The angle between the axes of the two neighboring windows was 90 degrees. Two opposite windows were used as the laser pathway. The other one window was used as the pathway for the camera to capture spray images. Last window was filled with a metal block. A singlehole type injector with the nozzle diameter of $0.14 \mathrm{~mm}$ was installed in an adapter in the center of the top lid of the vessel. A flat plate fixed perpendicular to the injector axis was located under the injector nozzle tip. A high pressure common rail injection system of Bosch was employed. The injector and common rail injection system were both controlled by an injection control equipment (EC94821ZZ, Changzhou automotive electronic systems Co., Ltd., ECTEK, China). The injection timing, injection mass and injection pressure were precisely controlled according to the need of experiments. A high-speed color camera (FASTCAM SA5, Photron Co., Japan) was equipped with a $100 \mathrm{~mm}, \mathrm{f} / 2.8 \mathrm{AF}$ lens (AT-X M100 PRO D Macro, Tokina, Japan) and two Barlow lenses with a magnification factor of three. The best resolution was approximately $14 \mu \mathrm{m} / \mathrm{pixel}$. The camera was controlled by another signal as same as the injection signal through a delay pulse generator (DG535, Stanford, USA), which can set the time to take images for the camera.

In order to measure the droplets from the oil film, a planar laser induced fluorescence (PLIF) technique was introduced. Prior to the fuel spray injection, a glycerine-water solution containing rhodamine B was arranged in the groove of the flat plate to form an oil film with known thickness, as shown in Figure 3. After the uniform thickness film was formed, the fuel spray was injected and impinged on the film. The fuel spray and the splashing droplets from the film were simultaneously illuminated by a continuous-wave (CW) laser (LE-LS-5321000TFCA, LEOPTICS, China) light sheet at $532 \mathrm{~nm}$. The laser sheet of $30 \mathrm{~mm}{ }^{*} 2 \mathrm{~mm}$ was formed by a laser beam through the cylindrical lens group. As the result of simultaneous 
illumination of the fuel spray droplets and splashing droplets from the film by the laser light sheet, the Mie-scattering from both the spray droplets and splashing oil droplets occurs. Simultaneously, the fluorescence signals from the splashing oil droplets are also emitted. Thus the camera perpendicular to the laser light plane photographed the two kinds of signals. Since the rhodamine B absorbed the laser light and fluoresced at a longer wavelength of 570 $\mathrm{nm}$, the fluorescence signals from the splashing oil droplets can be discriminated by the color in the collected RGB images by the camera. The fluorescence signals were shown as yellow and red with the corresponding RGB values, whereas the Mie-scattering signals were presented as green. Since the splashing oil droplets both emitted Mie-scattering and fluorescence signals, the spray droplets which only radiated scattered light can be distinguished. As shown in Figure 2, the green spray droplets (mainly inside the green dotted line circle) were removed in the processed image. From the images the diameter of droplets can be measured. Figure 2 displayes an example for calculating the diameter of a droplet. Moreover, the image data were analysed by using an open-source code, PIVlab [11], in MATLAB to obtain the velocity of droplets.

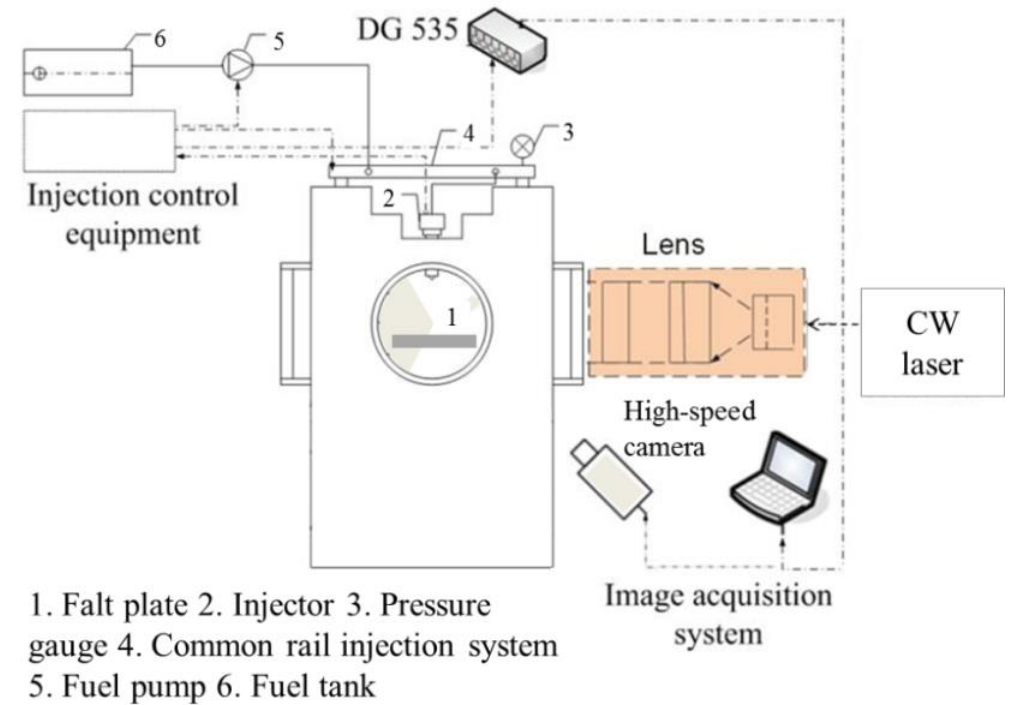

Figure 1. Schematic diagram of the experimental apparatus.

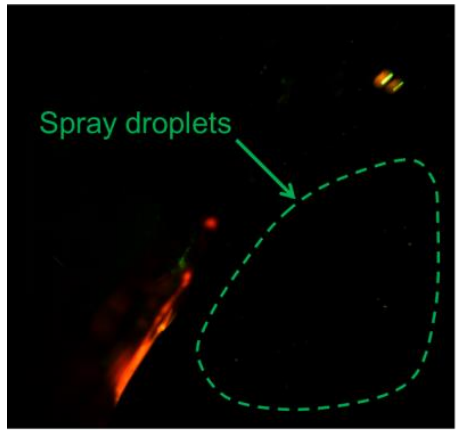

Original image

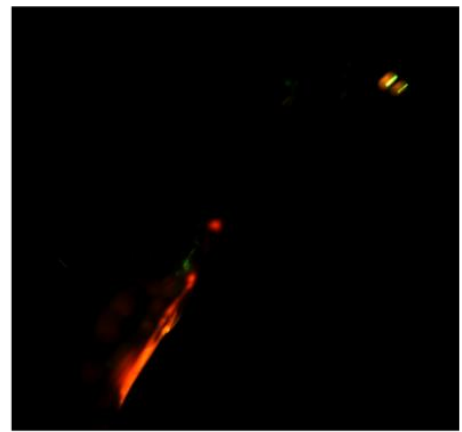

Processed image

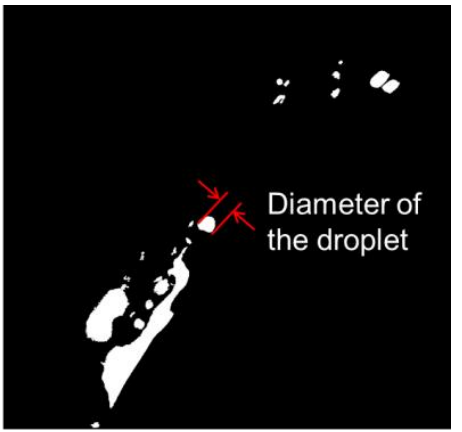

Binary image

Figure 2. Image processing process.

The specification of the wall, oil film and measurement locations is described detailly in Figure 3. Three kinds of glycerine-water solutions with different proportions were applied to form the oil film in the groove of the wall. Physical properties of the three kinds of oil film are summarized in Table 1, which are extracted from [12]. Kinematic viscosity and surface tension of a typical lubricant are also included in Table 1. The fuel used in this study is a 
mixture of $60 \%$ iso-octane and $40 \%$ n-heptane in volume. The selected five measurement locations are also illustrated in Figure 3. Table 2 shows the experimental conditions. As mentioned above, a single-hole type injector with the nozzle diameter of $0.14 \mathrm{~mm}$ was applied. The impingement distance was $33 \mathrm{~mm}$. The injection pressure was set as $60 \mathrm{MPa}$ and the injection duration of $1.25 \mathrm{~ms}$ was adopted. The ambient temperature was kept as $293 \mathrm{~K}$ and the ambient pressure was $0.1 \mathrm{MPa}$. The oil film thickness was varied as 0.2 and $0.5 \mathrm{~mm}$. In addition, the experiments were conducted at least five times under each measurement location and condition to obtain a repeatable result. The time of start of injection is defined as the initial time and ASOI means the time after start of injection.

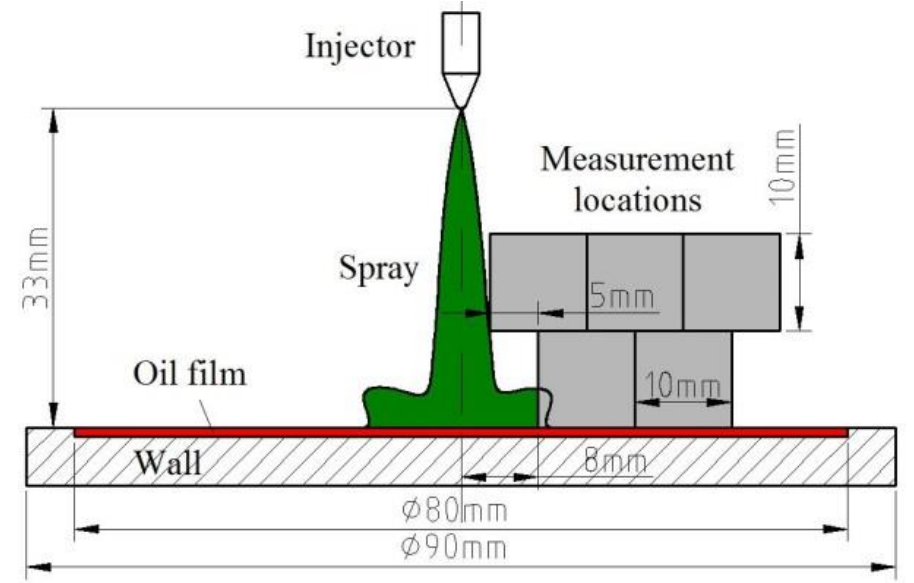

Figure 3. Specification of the wall, oil film and measurement locations.

Table 1 - Physical properties of the oil film.

\begin{tabular}{c|cccc}
\hline Oil & G48 & G63 & G70 & $\begin{array}{c}\text { Typical } \\
\text { lubricant }\end{array}$ \\
\hline $\begin{array}{c}\text { Glycerine mass } \\
\text { fraction/\% }\end{array}$ & 48 & 63 & 70 & $/$ \\
$\begin{array}{c}\text { Water mass fraction/\% } \\
\text { Kinematic } \\
\text { viscosity } / \mathrm{mm}^{2} \cdot \mathrm{s}^{-1}\end{array}$ & 52 & 37 & 30 & $/$ \\
Surface tension $/ \mathrm{mN}^{-1} \cdot \mathrm{m}^{-1}$ & 67.4 & 66.9 & 66.5 & $30[14]$
\end{tabular}

Table 2 - Experiment conditions.

\begin{tabular}{c|c}
\hline Parameters & Value \\
\hline Nozzle hole number & 1 \\
Nozzle hole diameter $/ \mathrm{mm}$ & 0.14 \\
Injection pressure, $P_{\mathrm{i}} / \mathrm{MPa}$ & 60 \\
Injection duration $/ \mathrm{ms}$ & 1.25 \\
Ambient temperature, $T_{\mathrm{a}} / \mathrm{K}$ & 293 \\
Ambient pressure, $P_{\mathrm{a}} / \mathrm{MPa}$ & 0.1 \\
Impingement distance, $\mathrm{L} / \mathrm{mm}$ & 33 \\
oil film thickness, $\delta / \mathrm{mm}$ & $0.2,0.5$
\end{tabular}

\section{Results and Discussion \\ Effects of viscosity}

Figure 4 depicts the splashing droplets behaviors from three kinds of oil film with different viscosities and $\delta=0.5 \mathrm{~mm}$ at $2.5 \mathrm{~ms}$ ASOI. The images of selected five measurement locations are presented together. At $2.5 \mathrm{~ms}$ ASOI, the spray has already impinged on the oil 
film and an obvious crown structure is generated. Above the crown, the droplet size is relatively large. However, there are more small droplets at the locations far from the crown. The significant difference among G48, G63 and G70 oil film is the size of crown structure. A remarkably lager crown is observed at G70 oil film condition. According to Table 1, the surface tension of three oil films is nearly identical, but the kinematic viscosity of G70 is higher than that of G63 and G48, which has a strong influence of splashing structure. Besides, some larger size droplets are generated at G70 oil film condition, due to the crown breakup. In the condition of droplets impinging on a wetted surface, the splashed product size also increases with the rise of fluid viscosity [3]. The buildup of fluid along the crown rim and subsequent breakup have been analyzed by the Rayleigh-Taylor instability theory [1517]. A high viscosity fluid will damp out impulsive motion and produce relatively smaller fluid front accelerations or decelerations than a lower viscosity one. Therefore, high viscosity fosters large wavelengths which are associated with the instability waves that develop. Alternately, the breakup is considered to be due to a capillary instability that causes breakup of a thin fluid jet [1]. In addition, the instability wavelength scales with Capillary number, which is itself proportional to the fluid viscosity.

In order to analyze the diameter distribution statistically, the probability density of splashing droplet diameter is employed, which was also applied by Mundo et al. [18] and Lacoste et al. [19]. The peak value of probability and the corresponding interval diameter suggest most droplets being with the certain diameter. The diameter of each droplet was calculated, and the probability of it should satisfy the normalization condition:

$\sum f_{N}\left(d_{i}\right)=1$

where the number of diameters between $d-\Delta d$ and $d$ is defined as $N(d), f_{N}\left(d_{i}\right)$ is the probability of $N\left(d_{i}\right)$ with $\Delta d$ being as $20 \mu \mathrm{m}$.

Moreover, the probability density of splashing droplet velocity is also considered. The definition is similar to the probability density of droplet diameter, as illustrated below:

$\sum f_{N}\left(v_{i}\right)=1$

where the number of droplet velocity between $v-\Delta v$ and $v$ is defined as $N(v), f_{N}\left(v_{i}\right)$ is the probability of $N\left(v_{i}\right)$ with $\Delta v$ being as $0.5 \mathrm{~m} / \mathrm{s}$.

Figure 5 shows the probability density of splashing droplet diameter and velocity from three kinds of oil film with different viscosities and $\delta=0.5 \mathrm{~mm}$ at $2.5 \mathrm{~ms}$ ASOI. In general, similar unimodal droplet diameter distribution curves of different oil films are observed. However, the curve moves toward the right and the diameter corresponding to the peak value of the curve increases from G48 to G70. The peak of splashing droplet diameter for G48 is about 40-60 $\mu \mathrm{m}$, which gradually rises to $60-80 \mu \mathrm{m}$ and $80-100 \mu \mathrm{m}$ for G63 and G70, respectively. The maximum droplet diameter also displays an increase trend with the rise of viscosity from G48 to G70. This can be explained by the fact that the higher viscosity inhibits the crown breakup process due to enhanced resistance to shear stress. Meanwhile, the maximum droplet velocity shows a contrary tendency. As the viscosity rises, the maximum droplet velocity declines. The velocity distribution of G48 is wider than that of G63 and G70, which means the difference of velocity between droplets is larger for G48.

\section{Effects of thickness}

Splashing droplets behaviors from two kinds of oil film with different thicknesses at $2.5 \mathrm{~ms}$ ASOI are described in Figure 6 . It reveals that a much smaller crown structure is generated at $\delta=0.2 \mathrm{~mm}$ compared to $\delta=0.5 \mathrm{~mm}$. The angle between the crown and wall surface is also smaller at $\delta=0.2 \mathrm{~mm}$. The thicker oil film will absorb more droplets from the incident spray rather than directing the impinging fluid into a radially directed flow. Thus the oil film will get 


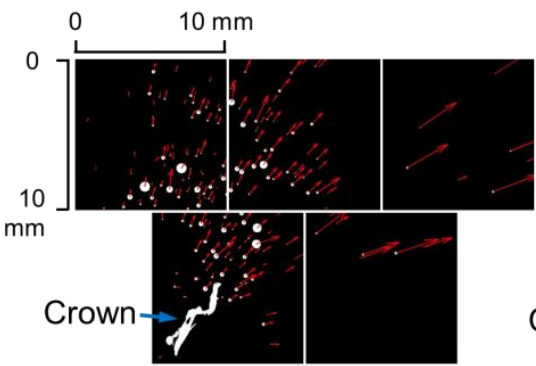

$\mathrm{G} 48, \delta=0.5 \mathrm{~mm}, 2.5 \mathrm{~ms}$ ASOI

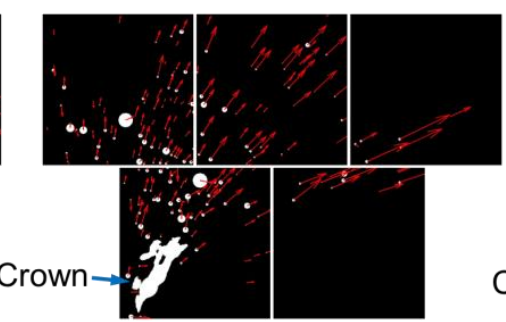

$\mathrm{G} 63, \delta=0.5 \mathrm{~mm}, 2.5 \mathrm{~ms}$ ASOI

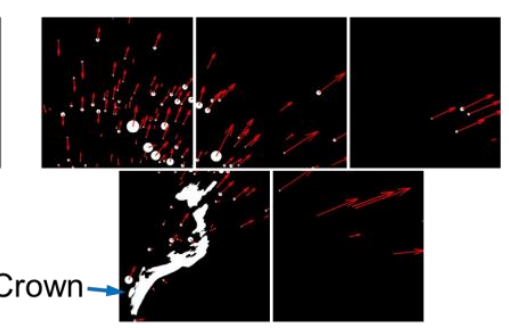

$\mathrm{G} 70, \delta=0.5 \mathrm{~mm}, 2.5 \mathrm{~ms}$ ASOI

Figure 4. Splashing droplets behaviors from three kinds of oil film with different viscosities and $\delta=0.5 \mathrm{~mm}$ at 2.5 ms ASOI.
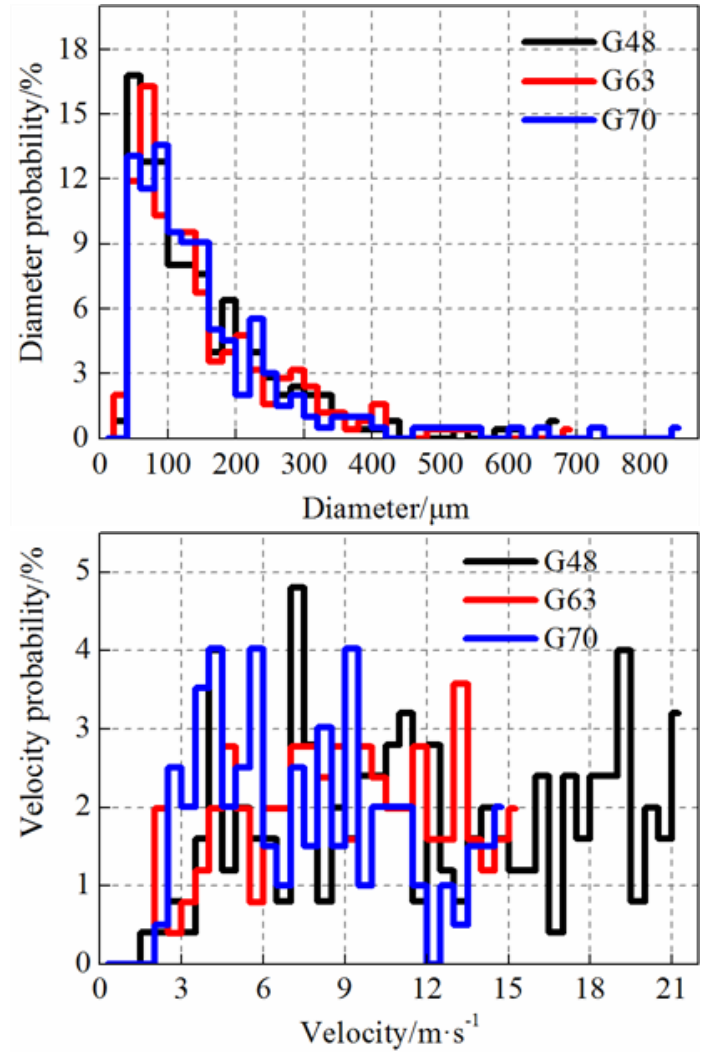

Figure 5. Probability density of splashing droplet diameter and velocity from three kinds of oil film with different viscosities and $\delta=0.5 \mathrm{~mm}$ at $2.5 \mathrm{~ms}$ ASOI.

more energy to facilitate the formation of larger crown structure. In comparison with $\delta=0.2$ $\mathrm{mm}$, more droplets with large size and low velocity are generated. The reason is that the larger crown has a strong ability to break into more droplets which have large diameter and low velocity. The smaller crown at $\delta=0.2 \mathrm{~mm}$ tends to break into relatively smaller droplets. Furthermore, a rising total number of droplets is observed at $\delta=0.5 \mathrm{~mm}$ than $\delta=0.2 \mathrm{~mm}$. In particular, there are a few droplets above the crown at $\delta=0.2 \mathrm{~mm}$. However, at $\delta=0.5 \mathrm{~mm}$, much more droplets are observed above the crown. The droplets at $\delta=0.2 \mathrm{~mm}$ have a smaller angle between the velocity direction and wall surface, namely more parallel to the wall. It is consistent with the tendency of crown structure.

Probability density of splashing droplet diameter and velocity from two kinds of oil film with different thicknesses at $2.5 \mathrm{~ms}$ ASOI is plotted in Figure 7. When the oil film thickness reduces from 0.5 to $0.2 \mathrm{~mm}$, the number of droplets with diameter above $300 \mu \mathrm{m}$ is greatly diminished. The condition of $\delta=0.2 \mathrm{~mm}$ shows a higher probability of relatively smaller droplets compared with $\delta=0.5 \mathrm{~mm}$. However, the diameters with maximum frequency are 
both around 80-100 $\mu \mathrm{m}$ for two film thicknesses. From $\delta=0.5 \mathrm{~mm}$ to $0.2 \mathrm{~mm}$, the peak value of 80-100 $\mu \mathrm{m}$ slightly decreases. Compared with $\delta=0.5 \mathrm{~mm}$, the splashing droplet velocity distribution range of $\delta=0.2 \mathrm{~mm}$ is increased, presumably it is on account of smaller size of the droplets. The maximum droplet velocity enlarges as the oil film thickness decreases.

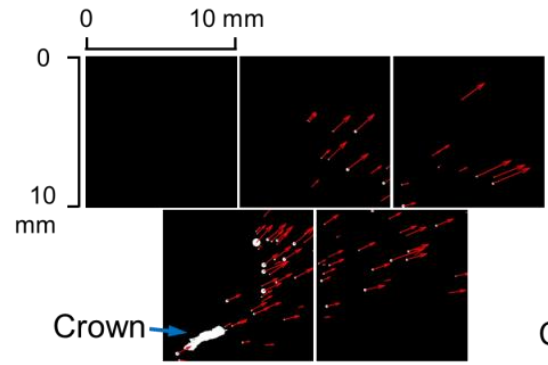

$\mathrm{G} 70, \delta=0.2 \mathrm{~mm}, 2.5 \mathrm{~ms}$ ASOI

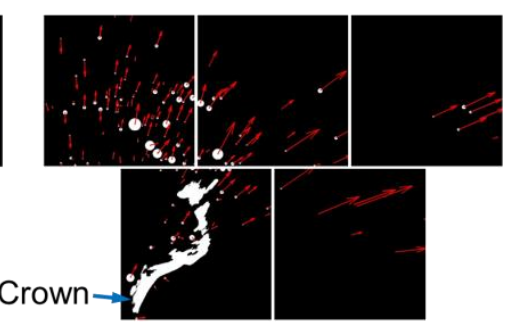

$\mathrm{G} 70, \delta=0.5 \mathrm{~mm}, 2.5 \mathrm{~ms}$ ASOI

Figure 6. Splashing droplets behaviors from two kinds of oil film with different thicknesses at $2.5 \mathrm{~ms}$ ASOI.

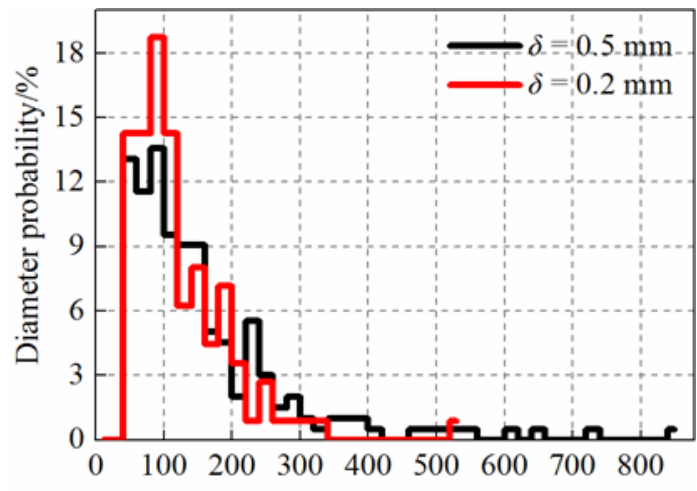

Diameter $/ \mu \mathrm{m}$

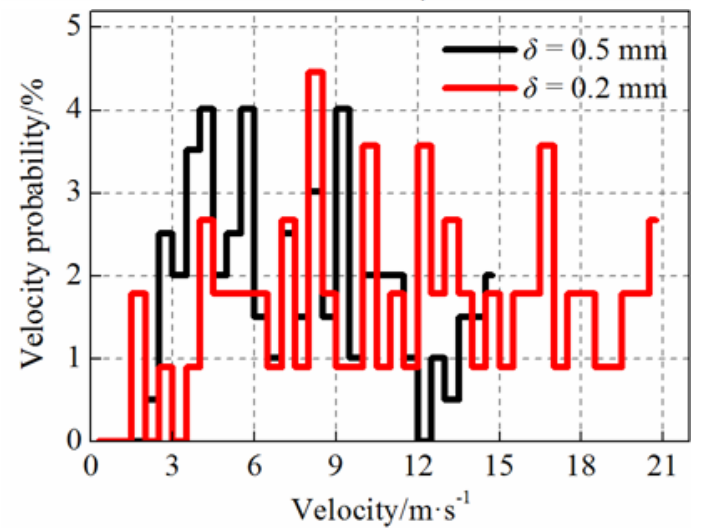

Figure 7. Probability density of splashing droplet diameter and velocity from two kinds of oil film with different thicknesses at $2.5 \mathrm{~ms}$ ASOI.

\section{Conclusions}

The droplet behaviors from the impinging spray and oil film are significantly important to evaluate the spray/film process and need to be deeply understood. In this study, under different viscosity and thickness of the oil film, the droplet behaviors from a spray after impinging on an oil film at different locations were analysed by planar laser induced fluorescence. The velocity of droplets was determined by using an open-source code, PIVlab, in MATLAB. The following conclusions can be drawn based on the observations:

1. An obvious crown structure is generated after the spray impinged on the oil film in the selected conditions.

2. With the rise of viscosity of the oil film, the crown size becomes larger and larger size droplets are generated. The droplet diameter with maximum frequency and the maximum 
droplet diameter both display an increase trend as the viscosity rises. However, the maximum droplet velocity declines.

3. The crown structure gets smaller and fewer droplets with large size and low velocity are generated when the oil film thickness declines from 0.5 to $0.2 \mathrm{~mm}$. The angle between the droplet velocity direction and wall surface also decreases as the oil film thickness reduces. Besides, a decreasing total number of droplets and a higher probability of relatively smaller droplets are observed at $\delta=0.2 \mathrm{~mm}$ compared with $\delta=0.5 \mathrm{~mm}$. On the contrary, the diameters with maximum frequency are comparable for two film thicknesses. The maximum droplet velocity enlarges as the oil film thickness decreases.

\section{Acknowledgments}

This work was supported by National Natural Science Foundation of China (NSFC) through the Project of 51922076 and 91941102.

\section{References}

[1] Yarin, A. L., and Weiss, D. A., 1995, "Impact of drops on solid surfaces: self-similar capillary waves, and splashing as a new type of kinematic discontinuity," J. Fluid Mech., 283, pp. 141-173.

[2] Rioboo, R., Bauthier, C., Conti, J., Voué, M., and De Coninck, J., 2003, "Experimental investigation of splash and crown formation during single drop impact on wetted surfaces," Exp. Fluids, 35(6), pp. 648-652.

[3] Vander Wal, R. L., Berger, G. M., and Mozes, S. D., 2006, "Droplets splashing upon films of the same fluid of various depths," Exp. Fluids, 40(1), pp. 33-52.

[4] Vander Wal, R. L., Berger, G. M., and Mozes, S. D., 2006, "The splash/non-splash boundary upon a dry surface and thin fluid film," Exp. Fluids, 40(1), pp. 53-59.

[5] Yu, H., Liang, X., Shu, G., Wang, Y., and Zhang, H., 2016, "Experimental investigation on spray-wall impingement characteristics of n-butanol/diesel blended fuels," Fuel, 182, pp. 248-258.

[6] Yu, H., Liang, X., Shu, G., Wang, X., Wang, Y., and Zhang, H., 2016, "Experimental Investigation on Wall Film Distribution of Dimethyl Ether/Diesel Blended Fuels Formed during Spray Wall Impingement," Energies, 9(11), p. 949.

[7] Zhang, H., Liang, X., Yu, H., Wang, Y., and Weijian, C., 2016, "Experimental Study on the Adhering Fuel Film of the Impinged N-Butanol-Diesel Blends," ASME 2016 International Mechanical Engineering Congress and Exposition(50589), p. V06AT08A006.

[8] Yu, H., Liang, X., Shu, G., Sun, X., and Zhang, H., 2017, "Experimental investigation on wall film ratio of diesel, butanol/diesel, DME/diesel and gasoline/diesel blended fuels during the spray wall impingement process," Fuel Process. Technol., 156, pp. 9-18.

[9] Liang, X., Zhang, H., Shu, G., Wang, Y., Sun, X., Yu, H., and Ge, M., 2018, "Experimental Investigation on Effect of Wall Roughness and Lubricant Film on the Adhered Fuel Film of N-Butanol-Diesel Blends after Spray Impingement," Energies, 11(6), p. 1576.

[10] Kambe, H., Mizobuchi, N., and Matsumura, E., 2017, "Simultaneous Measurement of Fuel Droplet Deposition Amount and Oil Film Thickness on Spray Impingement Using Double Laser Induced Fluorescence Method," SAE Technical Paper, 2017-01-2371.

[11] Thielicke, W., and Stamhuis, E., 2014, "PIVlab-towards user-friendly, affordable and accurate digital particle image velocimetry in MATLAB," Journal of open research software, 2(1).

[12] Lide, D. R., 2004, CRC handbook of chemistry and physics, CRC press.

[13] Manni, M., Gommellini, C., and Sabbioni, G., 1995, "Effect of Physical Characteristics of Lubricating Oils on Emissions, Fuel Economy and Oil Consumption in a Light Duty Diesel Engine," SAE Technical Paper, 952552.

[14] Bai, J., 2015, "Study on crankcase emissions and their formation of electric-controlled diesel engine," Ph.D., Shanghai Jiao Tong University, Shanghai, China.

[15] Thoroddsen, S. T., and Sakakibara, J., 1998, "Evolution of the fingering pattern of an impacting drop," Phys. Fluids, 10(6), pp. 1359-1374.

[16] Rieber, M., and Frohn, A., 1999, "A numerical study on the mechanism of splashing," Int. J. Heat Fluid Flow, 20(5), pp. 455-461.

[17] Bussmann, M., Chandra, S., and Mostaghimi, J., 2000, "Modeling the splash of a droplet impacting a solid surface," Phys. Fluids, 12(12), pp. 3121-3132.

[18] Mundo, C., Sommerfeld, M., and Tropea, C., 1995, "Droplet-wall collisions: Experimental studies of the deformation and breakup process," Int. J. Multiphase Flow, 21(2), pp. 151-173.

[19] Lacoste, J., Crua, C., Heikal, M., Kennaird, D., and Gold, M., 2003, "PDA Characterisation of Dense Diesel Sprays Using a Common-Rail Injection System," SAE Technical Paper, 2003-01-3085. 